\section{Biaética \\ Qual é o ReAl deSEjo humano frente À POSSIBILIDADE DE REPRODUÇÃO?}

Os avanços científicos e tecnológicos têm possibilitado a ampliação do conhecimento sobre o ambiente e o funcionamento do corpo humano, trazendo inúmeros benefícios à vida cotidiana do ser humano. Mas o quanto tem sido pensado sobre os efeitos do avanço científico para a humanidade no âmbito psicossocial?

Apossibilidade de reproduziréuma das definições devidae condição da preservação das espécies. Talvez, por estemotivo, tanto vem sendo investido na cura da infertilidade humana. São cada vez mais conhecidas as situações em que casais "biologicamente impossibilitados" deterem filhos recorremàs novastecnologias na busca detal realização de desejo, seja este ligado à vivência de uma gestação ou mesmo simplesmenteà preservação das características genéticas familiares.

Atualmente, no âmbito tecnológico, surgiu uma alternativa que tem sido bastante questionada: o transplante de útero. De acordo com publicação no Independent, médicos do New York Downtown Hospita / defendem o transplante como uma possibilidade de ajuda a mulheres que pretendem realizar o desejo de ser mãe. Concretamente, já estão sendo feitos cadastros de mulheres que pretendem realizar o transplante ainda este ano e de outras que aceitaram ser doadoras de útero em caso de morte cerebral.

\section{Comentário}

O que vem sendo discutido, no âmbito bioético, perante tais situações? A quem pertence a vida, seja pensando na doadora, na receptora ou mesmo no feto e, portanto, qual a autonomia das mulheres que pretendem se submetera tal procedimento? Os riscos dos procedimentos serão superados pelos benefícios das pessoas que poderão vir a ser "pais"? Quais os prejuízos e benefícios dos transplantes de útero frente a outras possibilidades equivalentes como a "barriga de aluguel"?

Seráquenão háuma questão maior dentro daperspectiva bioética? Seráque o papelda ciência nestes casos éapenas responderàsangústias humanas frente à impossibilidade de individuos terem um filho "naturalmente"? Por que apenas se questiona a condição emocional dos indivíduos perante a possibilidade de serem pais em casos de adoção, nos quais não háa intervenção da tecnologia? Por que a incapacidade biológica de gerar um filho reflete um questionamento da capacidade emocional da maternidade e da paternidade sónestes casos?

São muitas as questões, mas o que se pode perceber é que a humanidade tende compulsivamente a ampliar os seus limites biológicos, como na expectativa de vida e na possibilidade de fertilidade. Na fantasia induzida pela ciência de uma possível satisfação plena de vida, o ser humano consegue apenas deslocar as suas angústias.

\section{Claudio Cohen}

\section{Gisele Joana Gobbetti}

Referência

Connor S. Doctors screen women for first womb transplant (online). The Independent. Avaliable from: http://www.independent.co.uk. [cited 18 jan 2007].

\section{Clinica Cinürica \\ CONSEQÜENCIAS FISIOLÓGICAS, PSICOLÓGICAS E METABÓLICAS DA CIRURGIA BARIÁTRICA}

Os autores deste estudo fazem uma revisão da literatura analisando os resultados a longo prazo de pacientes submetidos a cirurgia bariátrica envolvendo quatro tipos de cirurgia: derivação em Y de Roux, gastroplastia com banda vertical, banda gástrica ajustável e diversão biliopancreática. A mortalidade pós-operatória variou de 0, 1 \% a 2\% nos diversos estudos. A perda de peso pós-operatória foi variável de acordo com cada tipo de cirurgia; no entanto, todas as técnicas se mostraram eficientes.

As principais alterações nos pacientes operados foram divididas pelos autores do estudo em setores de acordo com cada especialidade ou sistema.

I. Alterações respiratórias: Redução em quase $90 \%$ dos casos de asma e apnéia do sono. A redução das crises de asma foi atribuída à diminuição do refluxo gastroesofágico após o emagrecimento.

2. Alterações cardiovasculares e dos lípides: Houve diminuição das pressões sistólicas e diastólicas com conseqüente diminuição do risco de hipertensão e infarto. Além disso, houve diminuição acentuada do colesterol total, dos triglicérides, do ácido úrico e aumento da fração HDL do colesterol.

3. Alterações endócrinas: Nos pacientes submetidos a gastroplastia com redução de peso, houve uma diminuição importante das taxas de diabetes e do risco de aparecimento da doença nos não diabéticos.

4. Alterações gastrointestinais: Nos pacientes operados, as complicações gastrointestinais mais encontradas foram estenose da gastrojejunostomia, úlcera gástrica, fístulas gastrogástricas, obstrução intestinal de delgado, dumping, diarréia e vômitos. Também existe o risco de deficiências de ferro, vitamina B I 2, vitamina D e cálcio.

5. Alterações psiquiátricas: Com a perda de peso, ocorre um aumento da auto-estima, melhora do relacionamento social, diminuiçãa da ansiedade e da depressão.

Em conclusão, existem diversos benefícios que a perda de peso nos pacientes operados traz. Em acompanhamento a longo prazo, foram constatadas melhorias em nível cardiológico, respiratório, endócrino e psicológico. As complicações também são numerosas e geralmente estão associadas a deficiências nutricionais e complicações gastrointestinais.

A morbidade e mortalidade causadas pela obesidade podem ser tratadas convenientemente pela cirurgia bariátrica em pacientes apropriadamente selecionados.

\section{Comentário}

Os benefícios e complicações mostrados pelo estudo são constatados na prática diária de equipes bem estruturadas em nosso meio. Acreditamos que muitas das complicações vistas ultimamente poderiam ser evitadas com a melhor seleção de pacientes a serem operados. Faz-se, portanto, necessária a avaliação prévia dos candidatos à cirurgía bariátrica por equipe multidisciplinar competente.

Elias JiRJoss Ilias

Referência

Mango VL, Frishman WH. Physiologic, psychologic, and metabolic consequences of bariatric surgery. Cardiol Rev. 2006;14:232-7. 